Journal of Advanced Research in Fluid Mechanics and Thermal Sciences

Journal homepage: www.akademiabaru.com/arfmts.html ISSN: 2289-7879

\title{
Investigation on An Innovative Hydrocarbon Sensor for Real Drive Emissions
}

\author{
Muhammad Nor Azril Zulkafli ${ }^{1,2}$, Norazlianie Sazali ${ }^{1,}{ }^{,}$, Saiful Anwar Che Ghani ${ }^{1, *}$, Maurice Kettner ${ }^{2}$ \\ Faculty of Mechanical \& Automotive Engineering Technology, Universiti Malaysia Pahang, 26600 Pekan, Pahang, Malaysia \\ Hochschule Karlsruhe-Technik und Wirtschaft, Karlsruhe University of Applied Sciences, 76012 Karlsruhe, Germany
}

\section{ARTICLE INFO}

Article history:

Received 7 September 2020

Received in revised form 27 March 2021

Accepted 30 March 2021

Available online 12 July 2021

\section{Keywords:}

Hot water system; Hydraulic piping; Energy saving; Controller system

\section{ABSTRACT}

\section{Introduction}

European law specifies limit values for pollutant emissions from light duty vehicles and heavyduty engines including carbon monoxide (CO), hydrocarbons ( $\mathrm{HC}$ ), nitrogen oxide (NOx) and particulates, which are considered dangerous to human health. Historically, emission regulations focused only on diesel and petrol vehicles, specifying limit values for hydrocarbons and NOx, mostly due to concerns about smog and ozone formation in the atmosphere. The emitted hydrocarbon emissions (HCs) can currently only be measured with a flame ionization detector (FID) in the laboratory. Here, the oxidizable hydrocarbon compounds are ionized so that the detector signal is proportional to the carbon atoms supplied.

However, this measuring principle requires hydrogen $\left(\mathrm{H}_{2}\right)$, which must be stored in pressure vessels. Therefore, FID is a practicable solution for stationary test benches, but unsuitable for real

\footnotetext{
* Corresponding author.

E-mail address: azlianie@ump.edu.my

* Corresponding author.

E-mail address: anwarcg@ump.edu.my
}

https://doi.org/10.37934/arfmts.84.2.3949 
driving conditions. The different concentrations of propane gas (100ppm, 1000ppm, 4000ppm) and nitrogen gas $\left(\mathrm{N}_{2}\right)$ will be used on the hydrocarbon sensor. The idea is to calibrate the ion current measurement device to ensure that the feedback signals are ions coming from HC. Hydrocarbon emissions test is one of the important emissions tests that need to be done before releasing a new car in Europe. This is because many hydrocarbons have been classified as carcinogens, which is why their emissions are regulated and closely monitored in new engine designs. In September 2019, the value for hydrocarbon emission from light vehicles was standardized to $6 \mathrm{c} / 6 \mathrm{~d}$. Recently, the hydrocarbon emissions only can be tested in the laboratory because the tool used, flame ionization detector (FID), is only applicable in stationary tests but not in real driving.

$\mathrm{HC}$ emissions are the product of coal-hydrogen that is not or partially burned. These hydrocarbons are extracted from the engine's oil and lubricants. Emissions of hydrocarbons are narcotic and irritate the mucous membranes, depending on their composition. Many elements of HC emissions are also carcinogenic, such as aldehydes or benzene, and can have adverse health effects. $\mathrm{HC}$ emissions depend heavily on the ratio between air and gas. If this is less than 1 (rich mixture), there is a sharp increase in $\mathrm{HC}$ emissions as there is not enough oxygen required for the gas to be completely combusted. Emissions are also increasing at a ratio greater than 1 with a growing lambda $(\lambda)$. The explanation for this is that ignition and combustion failures will occur due to lower temperatures during combustion in homogeneous mixtures with increasing lambda $(\lambda)$. The mixture is not fully burned.

\section{Fundamental of Ion Current Measurement}

The approach of monitoring ion currents in flames has been widely known for ages. Volta discovered the electrical conductivity of free flame propagation in 1801 . This mechanism was widely explored in the early 1950s as one of the causes for burning hydrocarbons' high flame speed [1-4]. The physical and chemical properties of the combustion products inside the cylinder are related to the measured ion current $[5-11,15,16]$. The English physicist Gilbert discovered the electrical conductivity of flames by unloading an electroscope in an experiment through a flame. Work of ion current measurement began to gain traction in the 1960s and 1970s with great interest in combustion processes in rocket propulsion systems and application of the foundations of ion formation. Only since the end of the $20^{\text {th }}$ Century could ion current measurement be successfully achieved due to the reliability of engine fuel and the transient measurement technology with engines. The current ion calculation technology became significant in engine technology through numerical methods and computer-aided simulations [12]. The advantage of the ion current measurement technology is that the measurement is performed to the cylinder individually. It has therefore prevailed in massive, multi-cylindrical engines $[13,14]$.

\subsection{Gaseous Reactions}

Consider a gas has some free electrons that occur naturally. If a potential difference is applied across the gas, the resultant electric field will accelerate the free electrons. Along the way they collide with the interstitial gas atoms or molecules (M). Such collisions are chemical reactions and can be broadly classified into three classes that is illustrated as below

Elastic:

$e^{-}+M \rightarrow e^{-}+M$ 
Excitation:

$e^{-}+M \rightarrow e^{-}+M *$ iff $k_{e} \geq E_{M^{*}}$

Ionization:

$e^{-}+M \rightarrow 2 e^{-}+M+i$ ff $k_{e} \geq E_{\text {ion }}$

Note that, the kinetic energy of the incident electron $k_{e}$ must be greater than or equal to the minimum energy required for excitation $E_{M^{*}}$ or ionization $E_{i o n}$, respectively for the excitation and ionization reactions. Some of the kinetic energy of the incident electron either goes to the excitation state or ionize the target atom, where the collisions are inelastic and elastic, respectively.

\subsection{Ion Formation}

Due to the direct generation of measured values within the combustion chamber, the ion current technology provides a good basis for investigating the combustion process. The basis for the ion flow measurement is the conductivity of the gas mixture located in the chamber. By applying a voltage, for example by means of two electrodes, a current can be measured, depending on the conductivity, via a measuring resistance, which characterizes the processes occurring in the combustion chamber. The following are the basics of this technique and the signal progression that occurs during a combustion.

The condition of a current flow through ionization is that free charge carriers exist, and they move freely. These charge carriers can occur in the form of electrons, both positive and negative ions. The formation and destruction can take place in chemical ionization, thermal ionization, electron attachment and recombination. In addition, there is diffusion, in which concentration differences in a plasma lead to diffuse particles. However, this type of ion formation is less relevant in the combustion chamber and therefore will not be used further in this experiment.

\subsection{Effect of Temperature on The Gas Ionization}

The ionisation current is affected by a variety of engine characteristics, including temperature, air to fuel ratio, fuel type, E.G.R., by blow gases, engine load, and air humidity [15-19]. The ionization process occurred in the chamber due to presence of heat for the gas to be ionized. This is because the ceramic glow plug (CGP) in the chamber acts as heat input to the gas to be ionized. The kinetic energy of a gas molecule can be approximated by $K=\frac{3}{2} k_{B} T$ where $k_{B}$ is the Boltzmann constant $\left(\mathrm{k}_{B}=8.617343 \times 10^{-5} \mathrm{eV} / \mathrm{K}\right)$ and $\mathrm{T}$ is the gas temperature. From an order-of-magnitude analysis, $\mathrm{T}$ $\sim 105 \mathrm{~K}$ for a neutral to have kinetic energy approach that of the ionization energy $E_{\text {ion }} \sim 10 \mathrm{eV}$, for this phenomenon to be important the gas must be at extreme temperatures (thermal plasmas), and it is not relevant for non-equilibrium, low-temperature plasmas [20].

\section{Methodology}

\subsection{Simulation}

Thermal analysis in ANSYS Workbench is divided into three steps: pre-treatment; loading and solving; and post-processing

(i) Pre- treatment

First, define the name, title, and the system of units used, in which it is important to be prepared for a system of units of work, unified international standard unit is used to avoid 
some unnecessary trouble. Enter the pre-treatment stage, work to be done are select unit types, determine the unit options, set up a real constant, input material thermal properties, create geometry entity model, set the grid cell size, generate finite element analysis of grid cell.

(ii) Loading and Solving

Before solving, the ANSYS will load into a finite element model. After the completion of the loading options, select the solver. Solver is the function of solving simultaneous linear equations about structural degrees of freedom, this process may take a few seconds or to a few hours, largely depends on the speed of the computer used. Before solving, the data of inspection should be analysed.

(iii) Post processing

Operation can be evaluated through the establishment of model, meshing, loading and boundary conditions such as after a series of operations in thermal analysis model of ANSYS. By solving, the element temperature, heat flux, temperature gradient and so on a series of data can be observed.

In this project, thermal analysis of electrodes was investigated using ANSYS. The different materials such as stainless steel and structural steel are compared in this simulation. The aim is to observe the heat flux of each material which can help in the increase of ion current measurement reading.

\subsection{Experimental Setup}

\subsubsection{Resistance-temperature correlation experimental setup}

In this experimental set-up as shown in Figure 1 and Figure 2, the main ionization mechanism is the heat input that the gas experiences through the glow plug and thermal ionization. A quantitative statement about the temperature of the glow plug must be made to evaluate the heat input into the gas. The regulation of the temperature of the glow plug via the regulation of their resistance, which in turn depends on the adjustment of the current and the voltage of the power supply. Through studying the temperature and resistance relationship, it should be determined whether the glow plug resistance can control the temperature. An experiment was conducted to make a precise statement on the temperature of the glow plug. Since the resistance depends on the power supply voltage, the voltage of the glow plug ranged from $3.0 \mathrm{~V}$ in steps of $1.0 \mathrm{~V}$ to $6.0 \mathrm{~V}$.

The glow plug temperature is measured with a pyrometer, an optical instrument for the determination of temperature. This happens by measuring the thermal radiation emitted from the surface and evaluating the temperature by using defined boundary conditions such as material properties and geometric measurements. To obtain an accurate measurement, the pyrometer must be calibrated very precisely, and the measuring point must be adjusted.

Running experiment with flowing gas, the temperature cannot be determined by means of a pyrometer, since the housing covers the glow plug, and the pyrometer cannot optically determine the heat radiation emitted by the glow plug. 


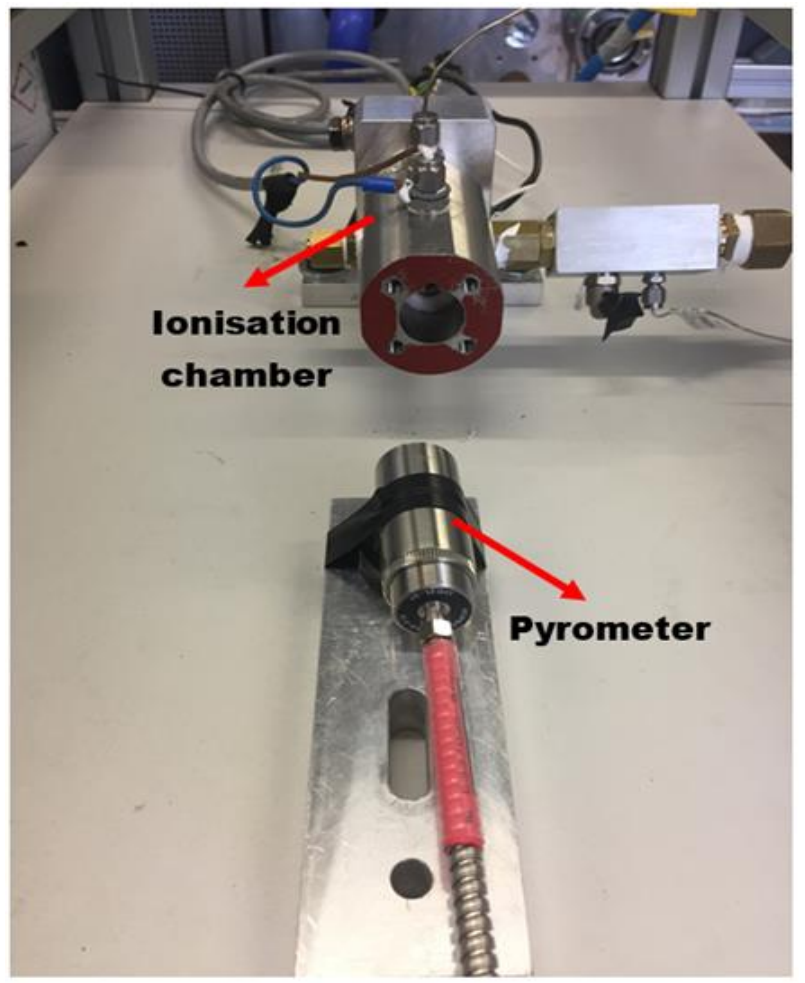

Fig. 1. Resistance-Temperature (RT) correlation experimental setup

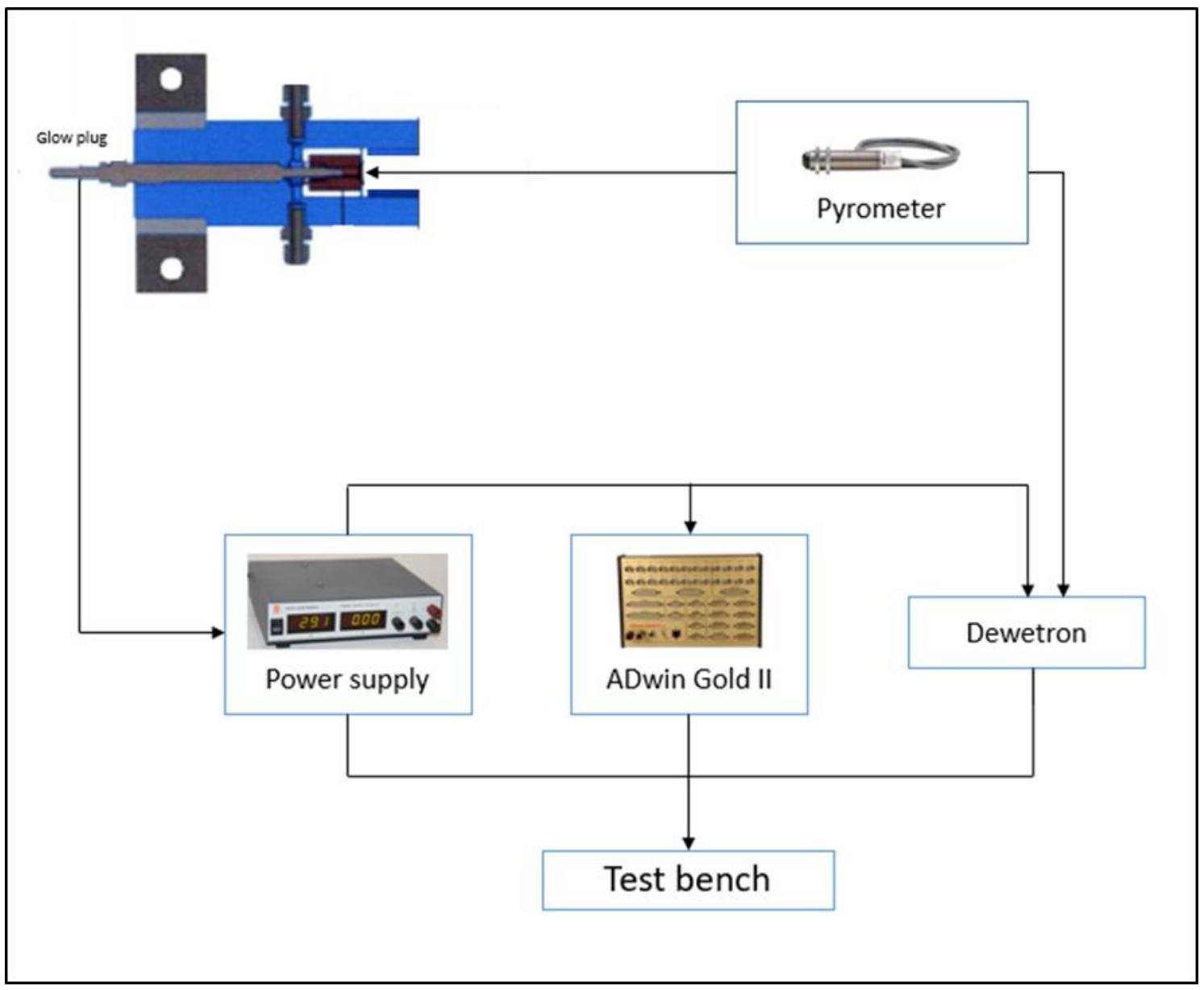

Fig. 2. RT- correlation experimental setup schematic diagram 


\subsubsection{Experimental process}

Figure 3 shows the experimental process of innovative HC sensor prototype.

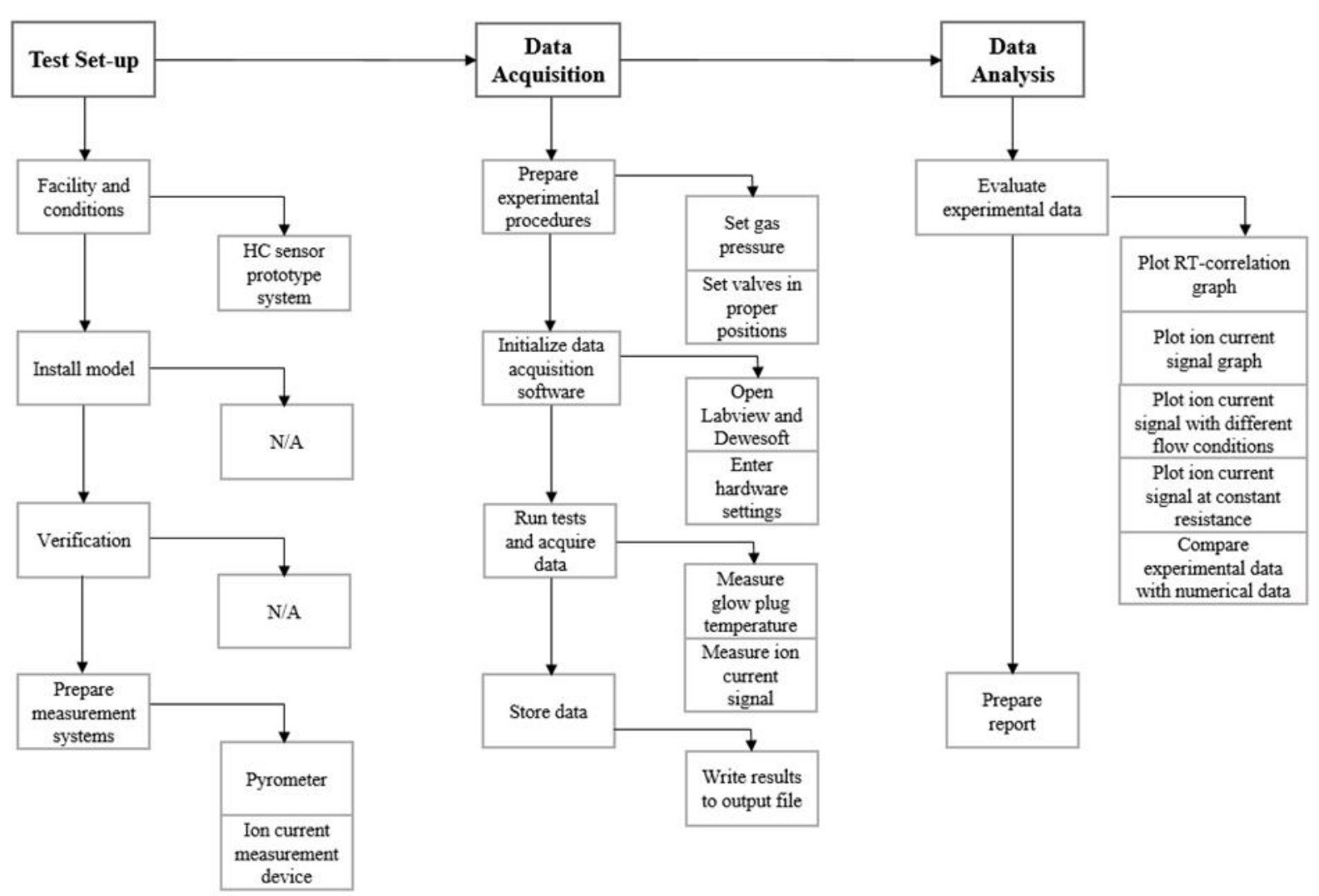

Fig. 3. Innovative $\mathrm{HC}$ sensor prototype experimental process

\section{Results and Discussion}

\subsection{Correlation Between Temperature and Resistance}

In order to control the temperature of the glow plug, the glow plug resistance must be determined. Due to the encapsulation in the sensor housing, direct determination is difficult. The idea is to regulate the temperature via the resistance of the glow plug [21]. Therefore, a resistancetemperature correlation is necessary to enable regulation via the resistance parameter.

The measurement data recorded is of one cycle taken at a constant time interval. The left side of the diagram in Figure 4 and Figure 5 show the variable that has been manipulated, for this test is the resistance $(\Omega)$. The responding variable, the glow plug temperature $\left({ }^{\circ} \mathrm{C}\right)$, is shown on the left side of the graph. The correlation between the resistance and temperature are determined with the help of a PID controller to manipulate the value of the resistance. To do this, the measurement data had to be averaged over the time of measurement and synchronized. The correlation factor can be determined precisely how the linearity of the measured points depends on each other. 


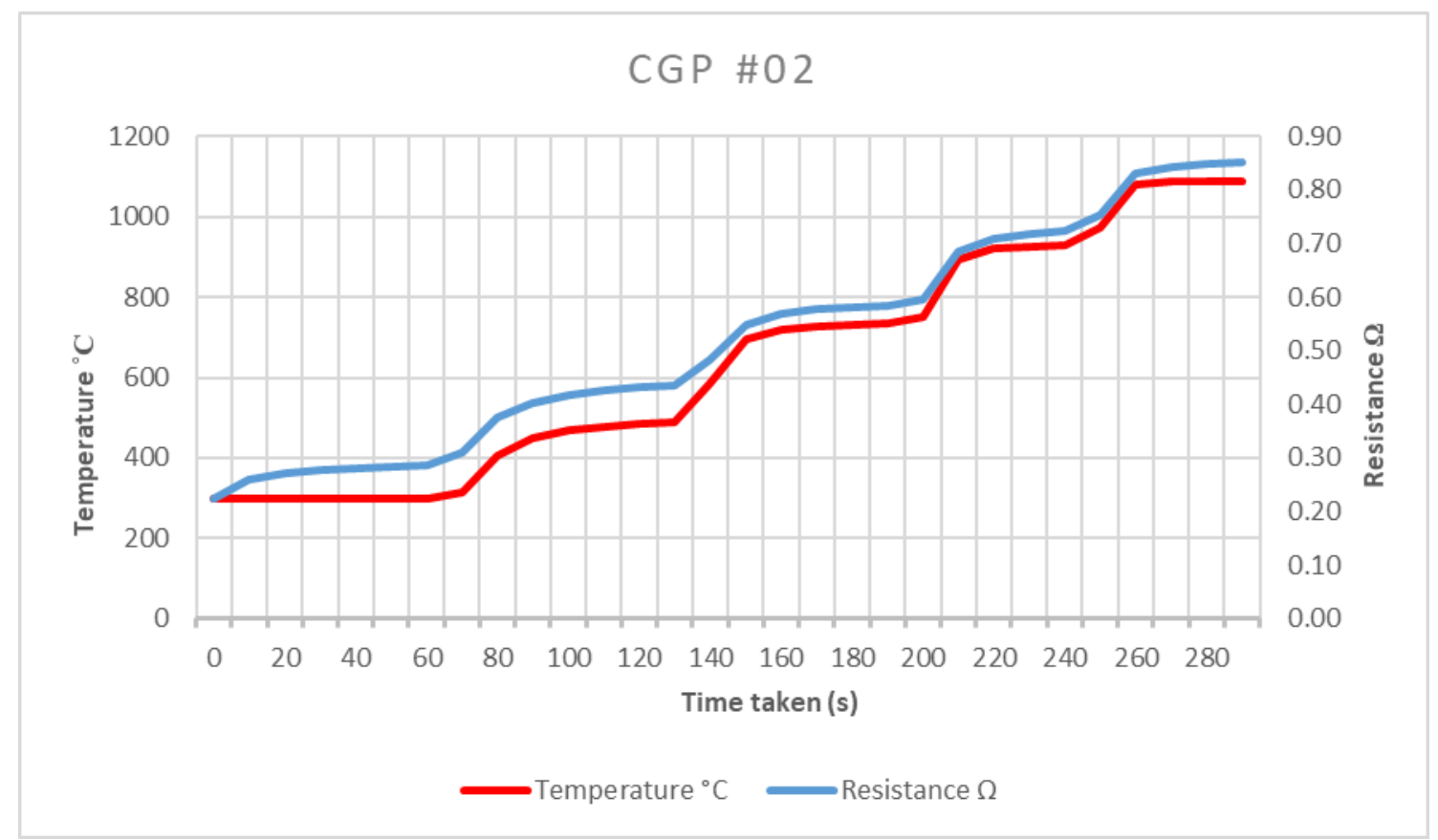

Fig. 4. RT correlation in under CGP \#02

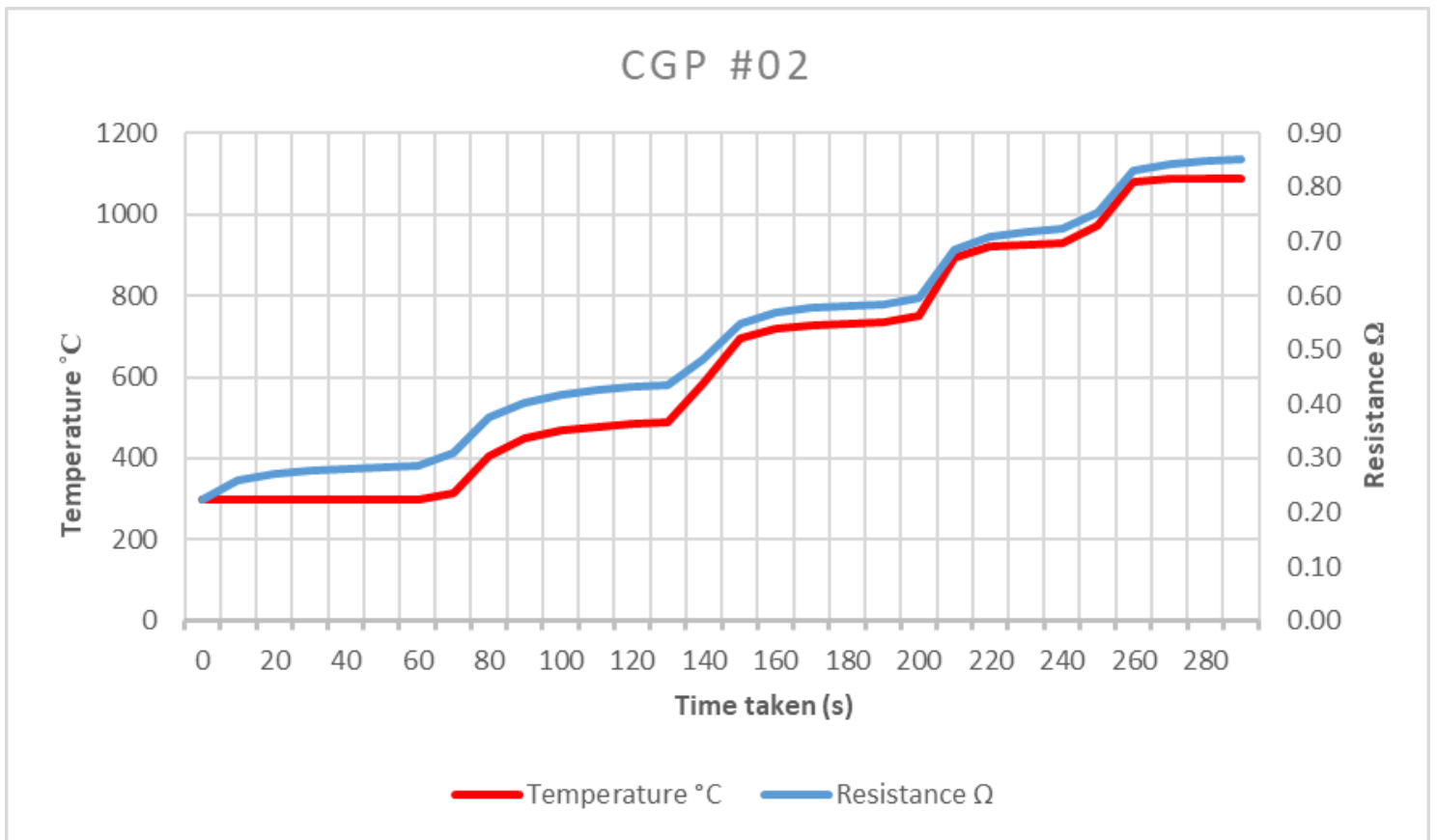

Fig. 5. RT correlation in under CGP \#28

The diagram shows a linear temperature dependence on the resistance in Figure 6 . The measured points are the big dotted line. From the plotted data, the correlation line generates a $y=m x+b$ function. The correlation factor is 0.9979 which shows that it is possible to describe the temperature measured here as linear function output. Therefore, the temperature is defined using the controlled resistor function. Conversely, the resistor may define temperature control as a very specific controlled parameter. 


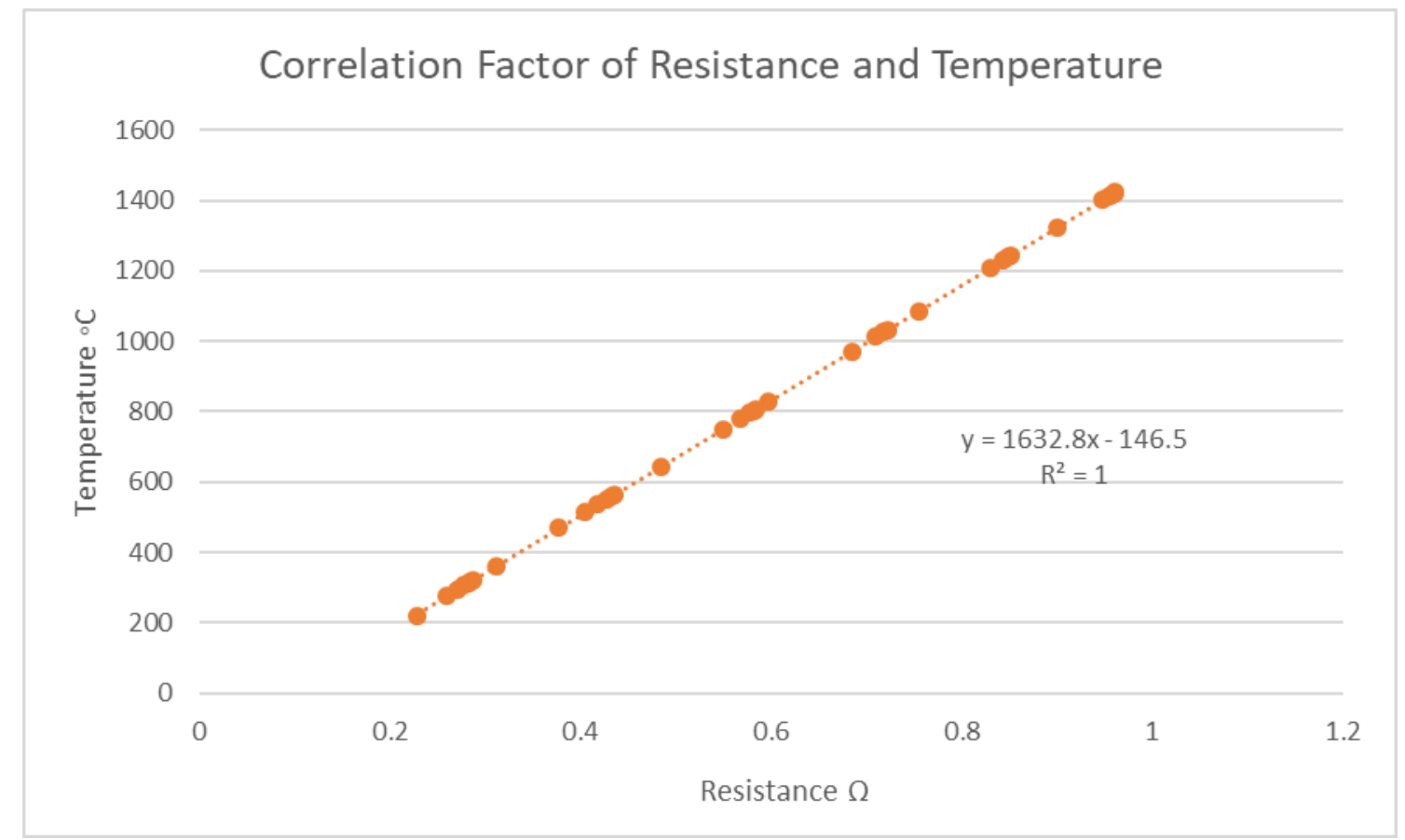

Fig. 6. Correlation factor of resistance and temperature

\subsubsection{Under flow conditions, $v \neq 0$}

For a better overview of the correlation between the resistance and temperature of the glow plug, the RT correlation experimental setup ran under flow conditions. This is to observe the behaviour of the glow plug temperature. In Figure 7, the graph shows the temperature of the glow plug decreases when there is air flow applied to the glow plug. It can be concluded that the air flowing acts as a cooling effect to the glow plug.

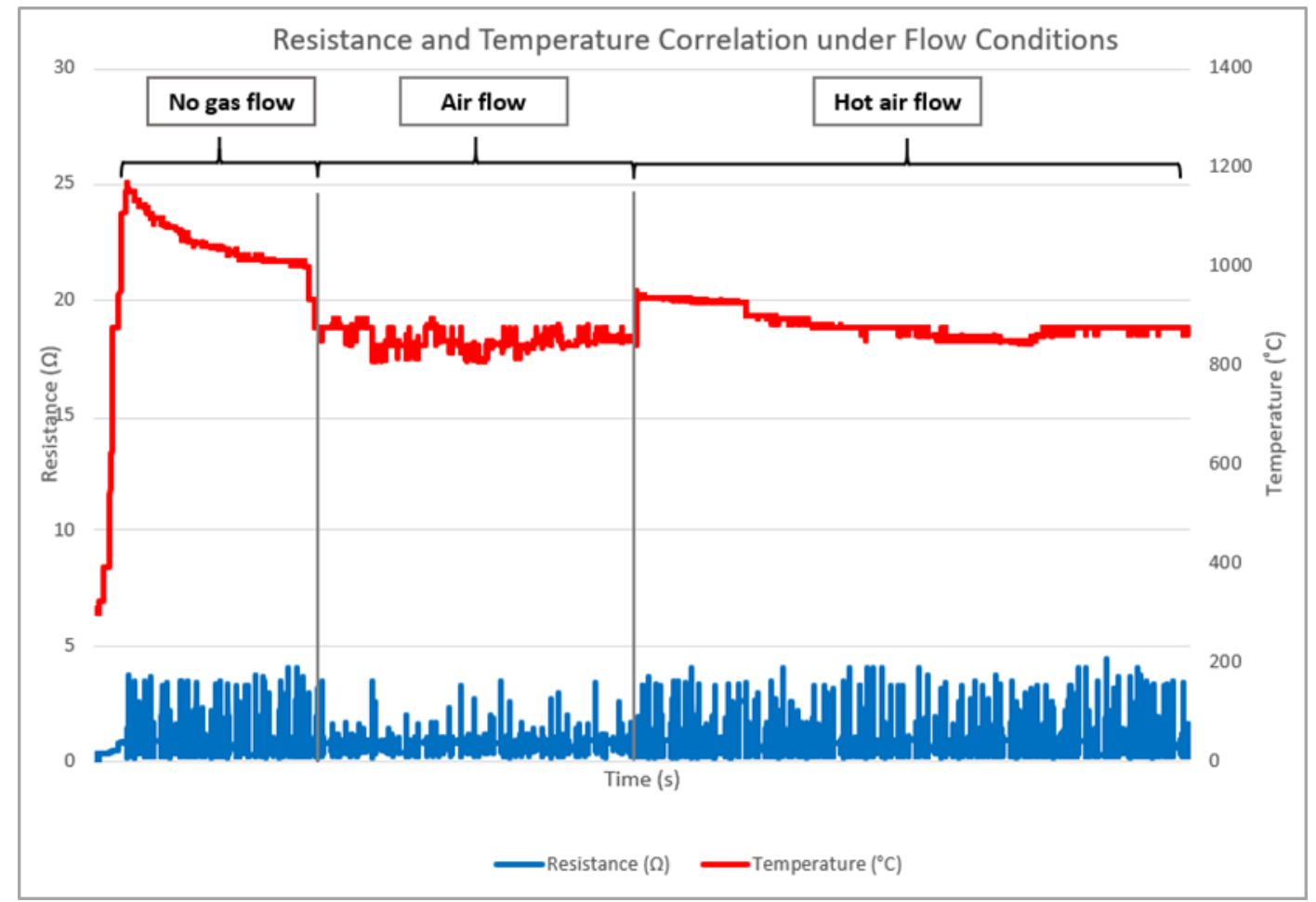

Fig. 7. RT correlation under flow conditions 


\subsection{Relationship Between Velocity and Ionization}

Since there is no flow meter to measure the gas velocity, a simple experiment was carried out to determine the mass flow rate of the propane gas that enters the chamber. From the mass flow rate of the propane gas, a comparison between experimental data and simulation data can be made. The pressure of the gas used in this experiment is 1 bar $(100 \mathrm{kPa})$. From calculation, the value of the gas velocity is $2.62 \mathrm{~m} / \mathrm{s}$. When the engine is running, the glow plug is cooled by the change in the charge and air movement in the compression phase. In [22], the author has mentioned that the behaviour of the gas flow is highly influence the ionization process.

The graph in Figure 8 and Figure 9 shows a nonlinear relationship between the velocity and the temperature. As the velocity of the mass flow increases, the temperature decreases.

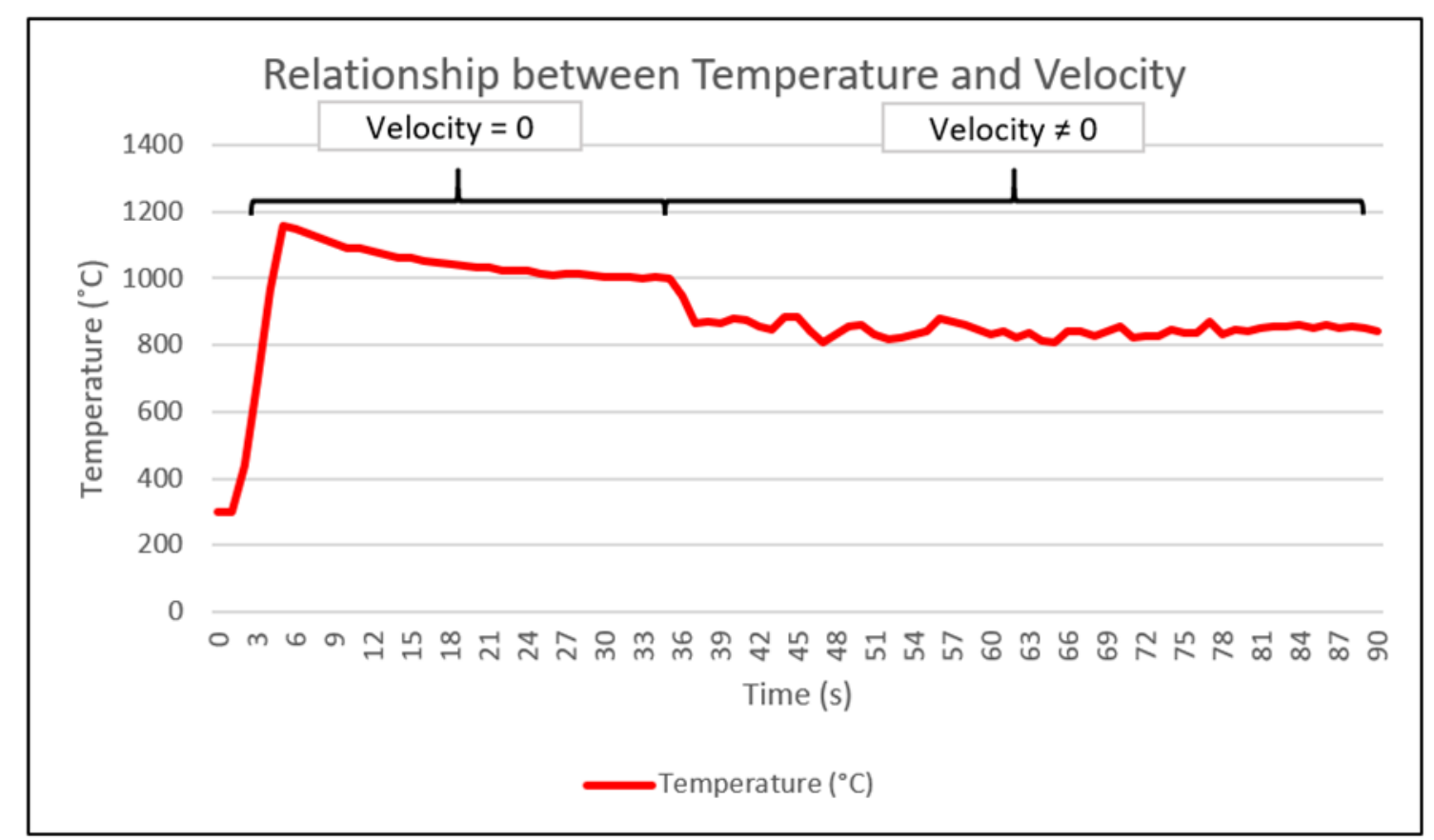

Fig. 8. Relationship between temperature and velocity
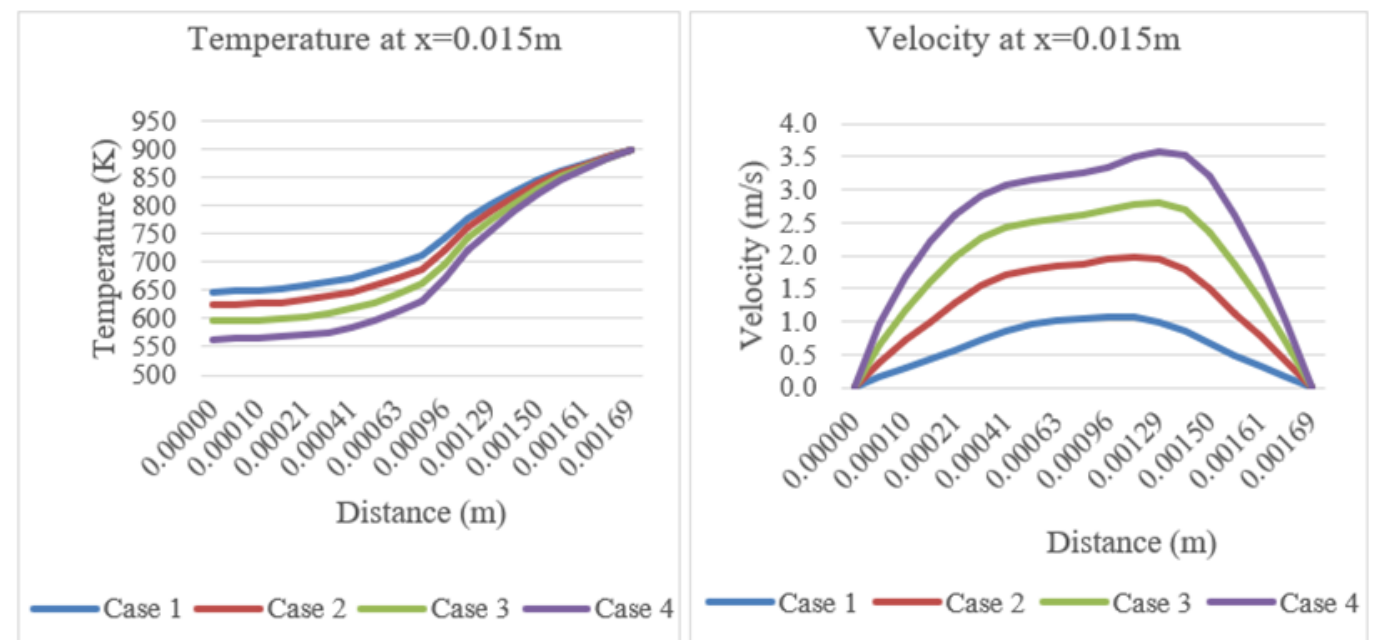

Fig. 9. Relationship between temperature and velocity 


\section{Conclusions}

Innovative hydrocarbon sensor prototype was built to improve the reliability of emission testing and possible application in future real drive emission tests. There are three factors that affect the ionization process in the hydrocarbon sensor chamber which are gas velocity, temperature, and gas concentrations. Through experiments in the laboratory with different gas concentrations of propane (100ppm, 1000ppm and 4000ppm) and normal air, the signal of ion current could be measured. However, the measurement of ion current signals can be measured when there is no air flow. This is because the flow makes the glow plug decrease in temperature. Furthermore, the ionization cannot take place in the chamber since the gas does not have enough time to be heated and ionized. Ion currents signal can be measured up to $10 \mathrm{~V}$ can be detected when used with high concentration of propane gas, which, in this case, is 4000 ppm gas concentration.

\section{Acknowledgement}

The authors would like to acknowledge the financial support from Universiti Malaysia Pahang and Hochschule Karlsruhe-Technik und Wirtschaft (HsKA) under grant number RDU192703 and UIC191514.

\section{References}

[1] Calcote, H. F. "Mechanisms for the formation of ions in flames." Combustion and Flame 1, no. 4 (1957): $385-403$. https://doi.org/10.1016/0010-2180(57)90001-9

[2] Calcote, H. F. "Ion production and recombination in flames." In Symposium (International) on Combustion, vol. 8, no. 1, pp. 184-199. Elsevier, 1961. https://doi.org/10.1016/S0082-0784(06)80502-3

[3] Anderson, Robert L. "In-Cylinder Measurement of Combustion Characteristics Using lonization Sensors." SAE Transactions (1986): 295-306. https://doi.org/10.4271/860485

[4] Shimasaki, Yuichi, Masaki Kanehiro, Shigeki Baba, Shigeru Maruyama, Takashi Hisaki, and Shigeru Miyata. Spark plug voltage analysis for monitoring combustion in an internal combustion engine. No. 930461. SAE Technical Paper, 1993. https://doi.org/10.4271/930461

[5] Auzins, John, Hasse Johansson, and Jan Nytomt. "Ion-gap sense in misfire detection, knock and engine control." SAE Transactions (1995): 1-8. https://doi.org/10.4271/950004

[6] Lee, Anson, and Jan S. Pyko. Engine misfire detection by ionization current monitoring. No. 950003. SAE Technical Paper, 1995. https://doi.org/10.4271/950003

[7] Collings, Nick, Steve Dinsdale, and Derek Eade. "Knock detection by means of the spark plug." SAE Transactions (1986): 969-974. https://doi.org/10.4271/860635

[8] Brehob, Deana D. An Exhaust Ionization Sensor for Detection of Late Combustion with EGR. No. 892084. SAE Technical Paper, 1989. https://doi.org/10.4271/892084

[9] Shamekhi, A. H., and A. Ghaffari. "Peak Pressure Position Estimation by lon Current Sensing, 10th Int." In Conf. of Mech. Eng, p. 608. 2002.

[10] Shamekhi, A. H., and A. Ghaffari. "Spark Advance Control by lon Current Sensing in SI Engines, 11th Int." In Conf. of Mech. Eng, p. 1908. 2003.

[11] Malaczynski, Gerard W., and Michael E. Baker. Real-time digital signal processing of ionization current for engine diagnostic and control. No. 2003-01-1119. SAE Technical Paper, 2003. https://doi.org/10.4271/2003-01-1119

[12] Shamekhi, Amir H., and Ali Gaffari. "Ionic Current Simulation During the Post Flame Period in SI Engines." In Internal Combustion Engine Division Fall Technical Conference, vol. 37467, pp. 223-228. 2004. https://doi.org/10.1115/ICEF2004-0820

[13] Basshuysen, Richard, and Fred Schäfer, eds. Handbuch Verbrennungsmotor: Grundlagen, Komponenten, Systeme, Perspektiven. Springer Fachmedien Wiesbaden, 2015. https://doi.org/10.1007/978-3-658-04678-1

[14] Wilstermann, Hartung. "Wechselspannungs-zuendung mit integrierter lonenstrommessung als Sensor fuer die Verbrennungs-und Motorregelung." Fortschritt Berichte-Vdi Reihe 12 Verkehrstechnik Fahrzeugtechnik (1999).

[15] Collings, Nick, and Ken Bray. "Ionization sensors for internal combustion engine diagnostics." Endeavour 15, no. 1 (1991): 10-12. https://doi.org/10.1016/0160-9327(91)90080-U

[16] Reinmann, Raymond, André Saitzkoff, Fabian Mauss, and Magnus Glavmo. "Local air-fuel ratio measurements using the spark plug as an ionization sensor." SAE Transactions (1997): 1224-1234. https://doi.org/10.4271/970856 
[17] Collings, Nick, Steve Dinsdale, and Tim Hands. "Plug fouling investigations on a running engine-an application of a novel multi-purpose diagnostic system based on the spark plug." SAE Transactions (1991): 681-686. https://doi.org/10.4271/912318

[18] Amann, Charles A. "Cylinder-pressure measurement and its use in engine research." SAE Transactions (1985): 418435. https://doi.org/10.4271/852067

[19] Kramer, M., and K. Wolf. "Approaches to gasoline engine control involving the use of ion current sensory analysis." Society of Automotive Engineers 905007 (1990).

[20] Go, David B. "Gaseous ionization and ion transport: An introduction to gas discharges." Department of Aerospace and Mechanical Engineering University of Notre Dame (2012).

[21] Scholl, Fino. "Study of premixed combustion induced by controlled hot surface ignition in stationary gas engines." PhD diss., Universidad de Valladolid, 2017.

[22] Rozy, Nurain, Norazlianie Sazali, Saiful Anwar Che Ghani, and Maurice Kettner. "Innovative Hydrocarbon Sensor for Real Drive Emission Testing: Optimization of the Gas Inlet." Journal of Advanced Research in Fluid Mechanics and Thermal Sciences 84, no. 1 (2021): 1-10. https://doi.org/10.37934/arfmts.84.1.110 